\title{
Study on Extraction and Conversion Annatto (Bixa orellana L.) Color into Norbixin to Prepare Food Grade Water-Soluble Norbixin Powder
}

\author{
Trần Thị Hà ${ }^{1}$, Đào Phan Thoại ${ }^{1}$, Lê Thị Thu Thủy ${ }^{1}$ and Phan Thế Đồng ${ }^{2}$ \\ 1. The Department of Food - Environment \& Nursing, Dong Nai Technology University, Dong Nai 810000, Viet Nam \\ 2. The Faculty of Science \& Engineering, Hoa Sen University, Ho Chi Minh 700000, Viet Nam
}

\begin{abstract}
Response surface methodology was used in this research to optimize the technical parameters of the extraction and conversion color compound in annatto seeds into norbixin. Parameters affected the extraction efficiency and norbixin recovery yield were solvent concentration, rate of solvent/seed, incubation time, and incubation temperature. The optimization results including: concentration of ethanol is $51.82^{\circ}$; concentration of $\mathrm{NaOH}$ is $0.52 \mathrm{M}$; ratio of solvent/seed is 7.1/1; incubation time is 33.12 minutes, incubation temperature is $58.6^{\circ} \mathrm{C}$, and the rate of $36 \% \mathrm{HCl} /$ color solution is $0.5 / 5(\mathrm{v} / \mathrm{v})$.
\end{abstract}

Key words: Achiote, Bixa orellana L., bixin, norbixin, extraction, conversion, food color.

\section{Introduction}

Bixa orellana L. which grows mostly in the tropics, is native to Central and South America, now widely grown in many tropical countries. In colonial period, Bixa orellana L. was imported to Vietnam, this plant grows wildly or is cultivated in the South, Central Highlands and Central to harvest seeds, ornamental or medicine [1]. The color of Annatto compound is extracted by cashews' nut (Bixa orellana L.). Annatto is a natural color that has been widely used for a long time in the traditional cuisine of many nations in the world. In the food industry, Annatto natural color is the second most important behind the caramel and is recognized by CODEX as food coloring and color safe pharmaceuticals. Bixin and norbixin are two major compounds building to Annatto. Bixin is insoluble in vegetable oil. Norbixin soluble in water at high $\mathrm{pH}$ becomes yellow to orange colour. The chemical structure of bixin ester group should be able to convert bixin and norbixin in cashew colored sodium or potassium salt of norbixin to increase solubility in

Corresponding author: Trần Thị Hà, M.Sc., lecturer, research fields: food safety, food additives. water [2-4], thereby increasing the usability of color annatto preparations.

\section{Experiment}

\subsection{Materials and Equipments}

Riped annatto seeds were purchased in Vinh Cuu district, Dong Nai province. After shelling, removing the impurities, floaters and small grains, seeds were dried in an oven at temperature of $40{ }^{\circ} \mathrm{C}$ until the moisture content reached about $10 \%$ as recommended by Mantovani et al. [5]. All chemicals used in research were of analytical grade.

\subsection{Research Methodology}

\subsubsection{Analysis of Norbixin}

Sample was weighed as $0.25 \mathrm{~g}( \pm 0.02 \mathrm{~g})$ (W) then dissolved by distilled water or appropriate solvent after that transferred into volumetric flask with a capacity of one liter. Next step, diluted by water or suitable solvent to the desired concentration, the concentration is depending on the concentration of the solution, and the last step, measuring the absorbance of the diluted solvent (A) (Distilled water or solvent 
were used as blanks).

Pigment content $(\%)=100 \times\left(\mathrm{A} / \mathrm{A}^{1 \%}{ }_{1 \mathrm{~cm}}\right) \times(\mathrm{F} / \mathrm{W})$

Among them:

A: absorbance of the diluted solution;

$\mathrm{A}^{1 \%}{ }_{1 \mathrm{~cm}}$ : absorbance of standard solutions $1 \%$ (the thickness of cuvette is $1 \mathrm{~cm}$ );

F: Factor of dilution ( $\mathrm{F}=$ volume of diluted solvent/volume of standard solvent);

$\mathrm{W}$ : volume of sample was diluted.

2.2.2. Evaluation Method Norbixin Free Recovery Yeild from Extractive Solvent

Add $5 \mathrm{~g}$ acid on extraction solvent, waiting deposited about 1 hour [6] then centrifuging to collect the precipitate of norbixin after that washing the precipitate dissolved, dissolved by $\mathrm{KOH}$ solvent $0.5 \%$ to volume extraction initial translation (5 g). Dissolve with $0.5 \% \mathrm{KOH}$ to measure the absorbance by wavelength at $482 \mathrm{~nm}$ (FAO JECFA, 2006). Extraction yield and norbixin recovery yield were calculated by the formula as below:

$$
\begin{aligned}
\text { Extraction yield }(\%) & =\left(\mathrm{m}_{1} \times 100\right) / \mathrm{m}_{0} \\
\text { Recovery yield }(\%) & =\left(\mathrm{m}_{2} \times 100\right) / \mathrm{m}
\end{aligned}
$$

Among them:

m: volume of Annatto contain in raw materials;

$\mathrm{m}_{0}$ : mass of dry matter contain in material;

$\mathrm{m}_{1}$ : mass norbixin be extracted;

$\mathrm{m}_{2}$ : mass of norbixin be extracted.

\subsubsection{Assessment of Solubility Method}

Following Santos' method (Barbosa and coworker, 2005), powder was stired lightly in water as 0.4 revs per minute until becoming a homogeneous solution then taking note of the time to dissolve. The time required less than 5 minutes was considerd as good powder.

\subsection{Conduct}

2.3.1 Optimizing Concentration of Solvent by Response Surface Method 2 Factors (Central Composite Design - CCD).

After weighing $5 \mathrm{~g}$ cashews the sample was stirred in solvent about 30 revs per minute then was incubated at $600{ }^{\circ} \mathrm{C}$ for 30 minutes. After filtering, take $1 \mathrm{~g}$ solvent to $1,000 \mathrm{~mL}$ of $0.5 \% \mathrm{KOH}$. Determining norbixin extraction yield (\%) by measuring at a wavelength of $482 \mathrm{~nm}$, experiments were illustrated by Table 1 .

2.3.2 Optimization Process Ratio of Solvent/Material and Conditions for Saponification Reaction by Response Surface Method 3 Elements (CCD)

The study was carried out as same as Section 2.3.1. The ratio of solvent/material, temperature $\left({ }^{\circ} \mathrm{C}\right)$, incubation time (minutes) were surveyed. Determining norbixin extraction yield (\%) was measured by wavelength at $482 \mathrm{~nm}$. Experiment is processed by Table 2.

2.3.3 Survey Volume of Concentrated Chlorhydric Acid to Precipitate Free Norbixin

Weigh of $5 \mathrm{~g}$ of the solution was extracted then drip solid acid 36\% in (solid acid was dripped slowly

\begin{tabular}{|c|c|c|c|c|c|}
\hline \multirow{2}{*}{ Elements } & \multicolumn{5}{|c|}{ Indicator variables } \\
\hline & $-\alpha$ & -1 & 0 & +1 & $+\alpha$ \\
\hline Concentration of ethanol $\left({ }^{\circ}\right)$ & 21.72 & 30 & 50 & 70 & 78.28 \\
\hline Concentration of $\mathrm{NaOH}(\mathrm{M})$ & 0.36 & 0.4 & 0.5 & 0.6 & 0.64 \\
\hline
\end{tabular}

Table 1 Survey with 2 factors.

Table 2 Survey with 3 factors.

\begin{tabular}{llllll}
\hline Elements & Survey & & & & \\
& $-\alpha$ & -1 & 0 & 6 & +1 \\
Ratio of solvent /material & 2.64 & 4 & 60 & 8 & 9.36 \\
Incubation temperature $\left({ }^{\circ} \mathrm{C}\right)$ & 43.2 & 50 & 30 & 40 & 76.8 \\
Incubation time (min) & 13.18 & 20 & 46.82 \\
\hline
\end{tabular}



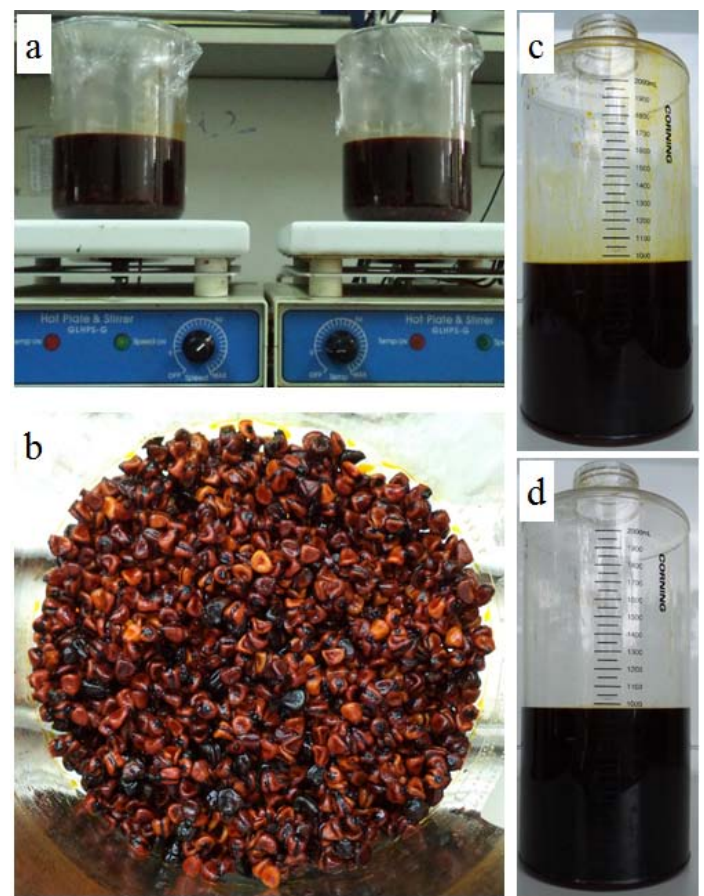

Fig. 1 Extracting and converting process into norbixin. (a: stirring process, b: waste matter, c: extractive solvent was filtered, d: extractive solvent was incubated).

into a centrifuge tube [7] volumes of centrifuge are 0.2, $0.25,0.3,0,35,0.4,0.45,0.5,0.55,0.6$ and $0.65 \mathrm{~mL}$, waiting for 1 hour and then centrifuged precipitate collected. Wash precipitates several times with distilled water. Dissolve the precipitate by $\mathrm{KOH} 0.5 \%$ into $5 \mathrm{~g}$. Take $1 \mathrm{~g}$ dilute to $1,000 \mathrm{~mL}$ of $0.5 \% \mathrm{KOH}$. Determine the norbixin free recovery yield (\%) by wavelength at $482 \mathrm{~nm}$.

\subsubsection{Design and Data Processing}

The experiment was designed by software JMP 9.0.2 program (SAS Institute Inc., 2011, USA), analysis of variance ANOVA, comparing average by Tukey's HSD method.

\section{Results and Discussion}

\subsection{Optimization Concentration of Solvent}

Results of extraction efficiency and color conversion in center point are higher than others. This is a sign that the optimum point can be located near the center survey.

Influence level of these factors and interactions each other on the response $\mathrm{Y}$ is illustrated and arranged on a Pareto chart (Fig. 2). Accordingly, influence level extraction efficiency yield and color conversion into norbixin descending as $\mathrm{X}_{1}{ }^{2}$ interactions have the greatest impact, followed by interactive $\mathrm{X}_{2}{ }^{2}$, the third is the concentration of $\mathrm{NaOH}$ $\left(\mathrm{X}_{2}\right)$, after the concentration of ethanol $\left(\mathrm{X}_{1}\right)$ and finally the interaction $\mathrm{X}_{1} \mathrm{X}_{2}$ not significantly affected. Thus, if you compare between ethanol and $\mathrm{NAOH}$, the effect of ethanol is important than $\mathrm{NaOH}$.

The relationship of the response $\mathrm{Y}$-extraction yield $\mathrm{X}_{1}$ - ethanol concentration $\mathrm{X}_{2}$-concentration of $\mathrm{NaOH}$ was demonstrated by equation as: $\mathrm{Y}=1.748+$ $0.06 \mathrm{X}_{1} \mathrm{X}_{2}+0.082-0.326 \mathrm{X}_{1}^{2}-\mathrm{X}_{2}^{2}$ 0.188. Response

Table 3 The result of experience.

\begin{tabular}{lllll}
\hline Variable & Encryption & $\begin{array}{l}\mathrm{X}_{1} \text {-concentration of } \\
\text { ethanol }\left({ }^{\circ}\right)\end{array}$ & $\begin{array}{l}\mathrm{X}_{2}-\text { concentration of } \\
\text { NaOH }(\mathrm{M})\end{array}$ & $\begin{array}{l}\text { Extraction of norbixin } \\
\text { yield }(\%)\end{array}$ \\
\hline 1 & -- & 30 & 0.4 & 1.14 \\
2 & -+ & 30 & 0.6 & 1.28 \\
3 & +- & 70 & 0.4 & 1.3 \\
4 & ++ & 70 & 0.6 & 1.42 \\
5 & $\mathrm{a} 0$ & 21.72 & 0.5 & 0.98 \\
6 & $\mathrm{~A} 0$ & 78.28 & 0.5 & 1.11 \\
7 & $0 \mathrm{a}$ & 50 & 0.36 & 1.18 \\
8 & $0 \mathrm{~A}$ & 50 & 0.64 & 1.46 \\
9 & 00 & 50 & 0.5 & 1.78 \\
10 & 00 & 50 & 0.5 & 1.74 \\
11 & 00 & 50 & 0.5 & 1.72 \\
12 & 00 & 50 & 0.5 & 1.7 \\
13 & 00 & 50 & 0.5 & 1.8 \\
\hline
\end{tabular}




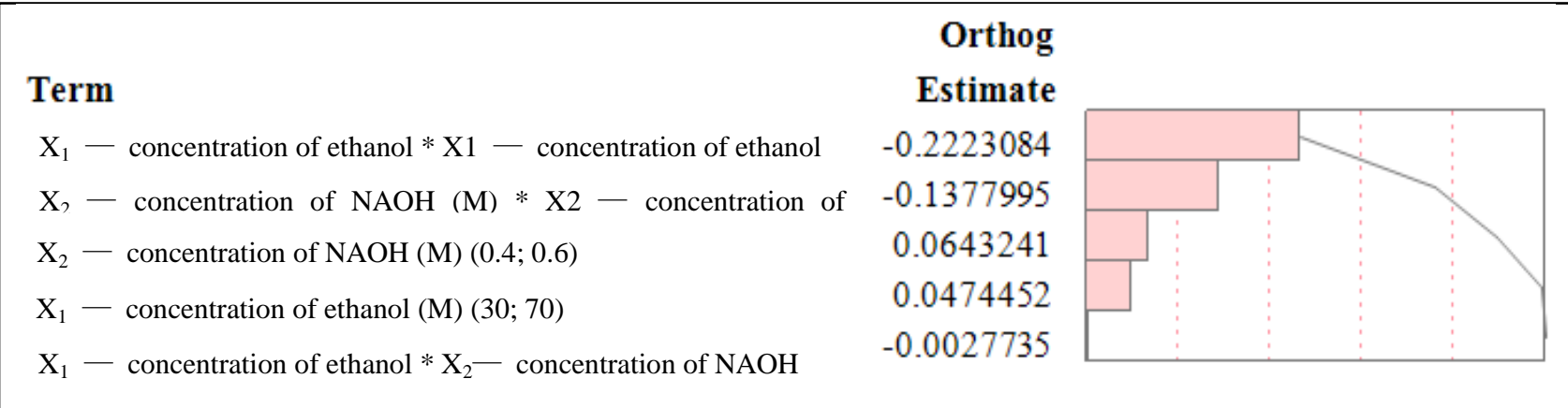

Fig. 2 Pareto chart showing the effects of these factors.

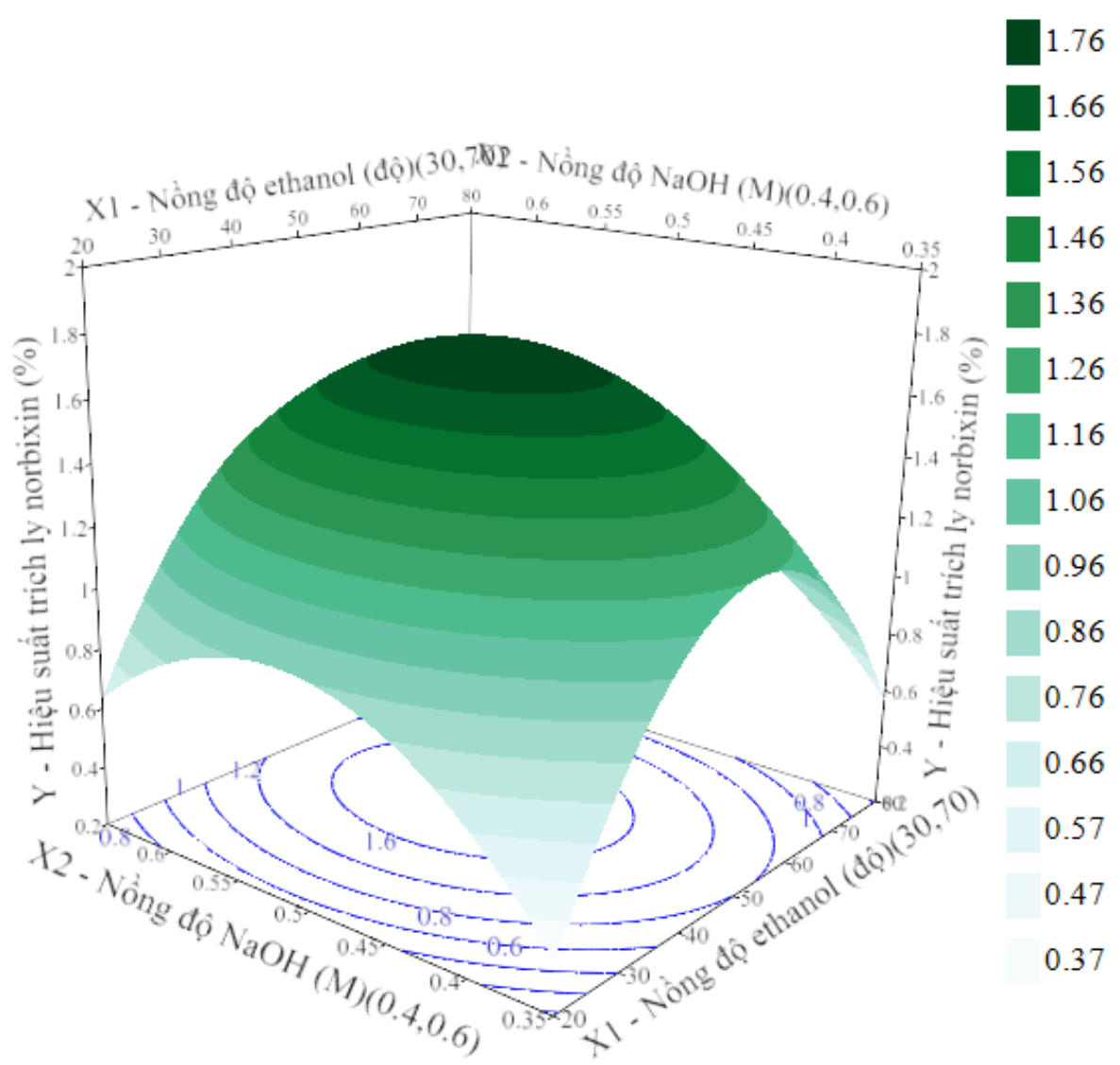

Fig. 3 Response surface showing the relationship between yield and concentration of two ingredients solvent.

surface shows the influence of the concentration of two-component solvent extraction performance and norbixin convert color to look like in Fig. 3. Surface above the peak point, i.e. extraction efficiency and norbixin color transformation into the highest range survey.

Optimal results are obtained and optimum concentration of ethanol $\left(51.82^{\circ}\right)$ and $\mathrm{NaOH}(0.52 \mathrm{M})$ will be used to conduct subsequent experiments as a basis for the construction and manufacturing processes.

3.2 Optimized Ratio of Solvent/Material and Reaction Conditions Saponification

After conducting experiments with random order, the results are summarized in Table 4 .

Overall, the results in Table 4 show that extraction efficiency and color conversion into the norbixin (from 15 to 20 treatments) at the solution in central is the best. This is a sign that the optimum point can be 
Table 4 Experimental results 3 CCD elements.

\begin{tabular}{llllll}
\hline Variable & Encryption & $\begin{array}{l}\mathrm{X}_{1} \text {-Ratio of } \\
\text { solvent/material }\end{array}$ & $\begin{array}{l}\mathrm{X}_{2} \text {-Incubation } \\
\text { temperature }\left({ }^{\circ} \mathrm{C}\right)\end{array}$ & $\begin{array}{l}\mathrm{X}_{3} \text { - Incubation time } \\
(\mathrm{min})\end{array}$ & $\begin{array}{l}\text { Y-Extraction of } \\
\text { norbixin yield }(\%)\end{array}$ \\
\hline 1 & --- & 4 & 50 & 20 & 1.03 \\
2 & --+ & 4 & 50 & 40 & 1.17 \\
3 & -+- & 7 & 70 & 40 & 0.83 \\
4 & -++ & 4 & 50 & 20 & 1.46 \\
5 & +- & 8 & 50 & 40 & 1.57 \\
6 & +-+ & 8 & 70 & 20 & 1.34 \\
7 & ++- & 70 & 40 & 1.46 \\
8 & +++ & 8 & 60 & 30 & 0.85 \\
9 & a00 & 2.64 & 60 & 30 & 1.59 \\
10 & A00 & 9.36 & 43.2 & 30 & 1.38 \\
11 & $0 \mathrm{a} 0$ & 6 & 76.8 & 30 & 1.28 \\
12 & $0 \mathrm{~A} 0$ & 6 & 60 & 13.18 & 0.98 \\
13 & $00 \mathrm{a}$ & 6 & 60 & 46.82 & 1.6 \\
14 & $00 \mathrm{~A}$ & 6 & 60 & 30 & 1.8 \\
15 & 000 & 6 & 60 & 30 & 1.69 \\
16 & 000 & 6 & 60 & 30 & 1.78 \\
17 & 000 & 6 & 60 & 30 & 1.82 \\
18 & 000 & 6 & 60 & 30 & 1.75 \\
\hline 19 & 000 & 6 & & 30 & 1.82 \\
\hline
\end{tabular}

\begin{tabular}{|c|c|}
\hline Term & $\begin{array}{r}\text { Orthog } \\
\text { Estimate }\end{array}$ \\
\hline $\mathrm{X}_{1}-$ Ratio of solvent/material (4/8) & 0.1854270 \\
\hline $\mathrm{X}_{3}-$ Incubation time (min)* $\mathrm{X}_{3}-$ Incubation time (min) & -0.1496169 \\
\hline $\mathrm{X}_{1}-$ Ratio of solvent/material $* \mathrm{X}_{1}-$ Ratio of solvent/material (4.8) & -0.1459964 \\
\hline $\mathrm{X}_{2}$ - Incubation temperature $\left({ }^{\circ} \mathrm{C}\right) * \mathrm{X}_{3}-$ Incubation temperature $\left({ }^{\circ} \mathrm{C}\right)$ & -0.1233658 \\
\hline $\mathrm{X}_{3}-$ Incubation time $(\min )(20.40)$ & 0.0945559 \\
\hline $\mathrm{X}_{2}-$ Incubation temperature $\left(50.70^{\circ} \mathrm{C}\right)$ & -0.0476908 \\
\hline $\mathrm{X}_{1}-$ Ratio of solvent/material $* \mathrm{X}_{2}$ - Incubation temperature (min) & 0.0126491 \\
\hline $\mathrm{X} 1$ - Ratio of solvent/material $* \mathrm{X}_{3}$ - Incubation time (min) & -0.0047434 \\
\hline $\mathrm{X}_{2}$ - Incubation temperature $\left(50.70^{\circ} \mathrm{C}\right) * \mathrm{X}_{3}-$ Incubation time (min) & 0.0015811 \\
\hline
\end{tabular}

Fig. 4 Pareto chart showing the effects of these factors.

located near the center survey. Influence level of these factors and their interactions on the response $\mathrm{Y}$ is illustrated and arranged on a Pareto chart (Fig. 4). Accordingly, extraction efficiency and color conversion into norbixin are as follows: $\mathrm{X} 1$-the ratio of solvent/Most affected grain, $\mathrm{X}_{3}{ }^{2}$ interaction affects less than second place, followed by interactive $\mathrm{X}_{1}{ }^{2}$ and $\mathrm{X}_{2}{ }^{2}$, then the annealing time and temperature of incubation $\mathrm{X}_{2} \mathrm{X}_{3}, 3$ pairs of interacting pairs of 3 factors significantly influence the performance extracted and converted into norbixin color. Thus, if you compare the effects of three factors, the impact of the rate of extraction efficiency and color conversion into the more important norbixin incubation time, incubation temperature was at number 3 most influential factors in survey . 

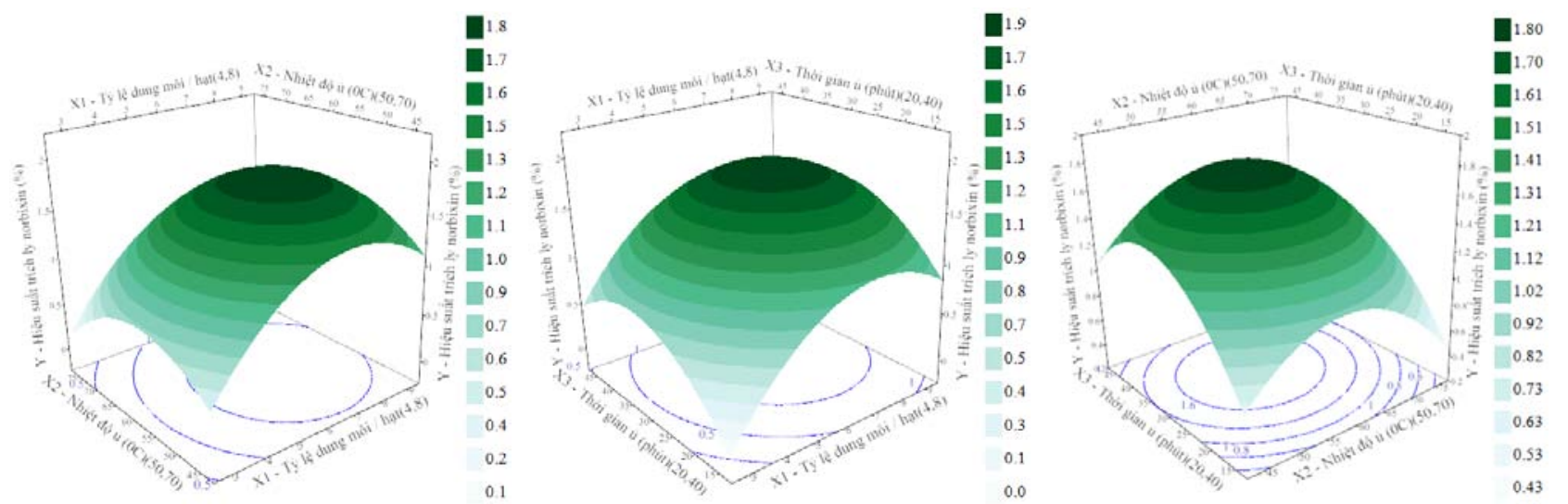

Fig. 5 Response surface showing the correlation between the extraction efficiency between: (a) annealing temperature and the ratio of solvent/seed; (b) incubation time and the ratio of solvent/seed; (c) annealing temperature and time.

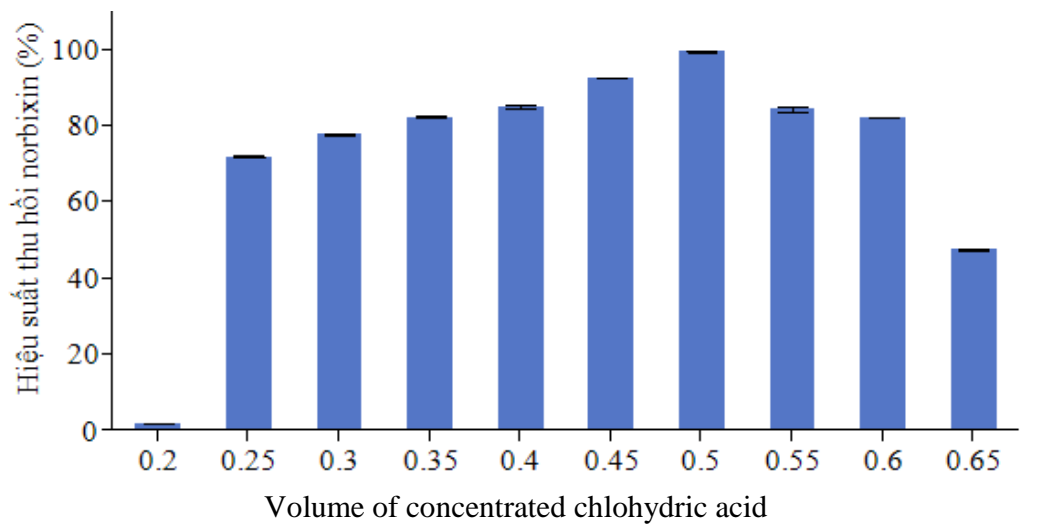

Fig. 6 Influence of volume of $36 \%$ chlohydric acid recovery performance norbixin.

The results obtained can represent the relationship between the response $\mathrm{Y}$ - Extraction yield and convert color into 3 elements norbixin with X1-ratio solvent / particle, $\mathrm{X}_{2}-\mathrm{X}_{3}$ and annealing temperature- incubation time by the following regression equation: $\mathrm{Y}=1.777$ $+0.224 X_{1}-0.058 X_{2}+0.114 X_{3}-0.2010 .162$ $\mathrm{X}_{1}^{2}-\mathrm{X}_{2}^{2}-\mathrm{X}_{3}^{2}$ 0.176. Response surface corresponding to each pair of elements is shown in Fig. 5, the response surface on the top side, i.e. the highest performance ranges.

The result shows that the optimum solvent ratio/seed is $7.1 / 1,58.58{ }^{\circ} \mathrm{C}$ annealing temperature and annealing time is 33.12 minutes, while the extraction efficiency and color conversion into norbixin estimated $1.86 \%$; equivalent to $86.92 \%$ recovery efficiency. Optimal parameters are consistent with the recommendations of Nachtigall et al. [3] that the implementation of the saponification reaction of bixin norbixin should not raise the temperature too high for a long time, the temperature should be below $70{ }^{\circ} \mathrm{C}$ and shorter time to 1 hour.

\subsection{Effect of Hydrochloric Acid Concentration to Precipitate Free Norbixin}

The survey of the impact of volume of $36 \% \mathrm{HCl}$ acid on norbixin retrieval performance is shown in Fig. 6.

The average results comparing with Tukey's HSD method showed that the volume of concentrated hydrochloric acid precipitates the best norbixin 0.5 $\mathrm{mL}$ and mean differences with retrieval performance when using different volumes of $\mathrm{HCl}$ in $p=0.05$ level. The amount of fluid extracted in each treatment is $5 \mathrm{~g}$ ( $5.43 \mathrm{~mL}$ ), then $0.5 \mathrm{~mL}$ of $36 \% \mathrm{HCl}$ when dissolved in translation extract equivalent to a concentration of $1 \mathrm{M}$. This result is consistent with the method of Dinda 


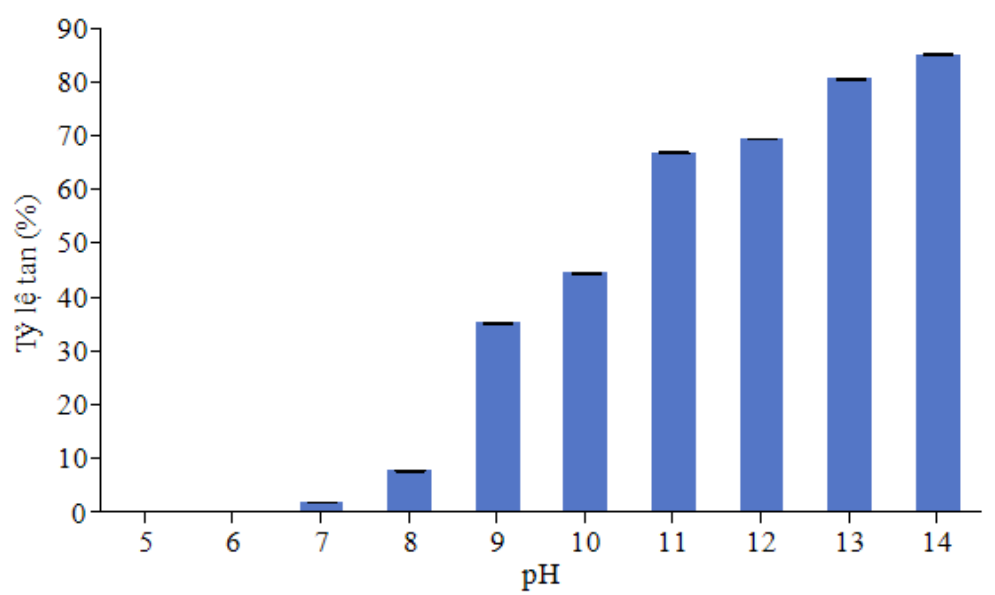

Fig. 7 Norbixin ratio dissolved in water at different $\mathrm{pH}$.

et al. [8] when the authors use dilute hydrochloric acid to precipitate norbixin obtained after solvent extraction with $5 \% \mathrm{KOH}$.

\subsection{Solubility of the Powder Precipitated at $\mathrm{pH}$ Norbixin in Different Countries}

Using $0.1 \mathrm{~g}$ norbixin precipitated dough for each treatment to the survey conducted in water solubility of precipitated dough norbixin at different $\mathrm{pH}$ values, the results are shown in Fig. 7.

After comparing the average rate of melting of norbixin at different $\mathrm{pH}$ by means of Tukey's HSD it showed that only at $\mathrm{pH} 5$ and 6 percentage tan difference not significant, the remaining percentage tan differences significant pairs. Thus norbixin precipitated powder soluble in water at a $\mathrm{pH}$ below 7 , while at $\mathrm{pH}$ above 7 , the melting rate is proportional to the $\mathrm{pH}$ value. Experimental results with the correct reference information about the solubility of the precipitate norbixin powder in water [8], the reason is freedom in powder precipitated norbixin have long hydrophobic carbon vessels, namely HLB value is 2.65 lower than 7.

\section{Conclusion}

Annatto colour in Vietnam's annatto seeds can be extracted and converted into ethanol solvent norbixin alkaline by $\mathrm{NaOH}$. The recovery of $87 \%$ at best in the conditions are as follows: ethanol concentration of $51.82^{\circ}$; concentration of $0.52 \mathrm{M} \mathrm{NaOH}$; ratio of solvent/material is $7.1 / 1$; annealing temperature and time respectively $58.6{ }^{\circ} \mathrm{C}$ and 33.12 minutes. After extraction, norbixin freedom can be separated from the service by means of acid extraction chemistry. Concentration of $1 \mathrm{M}$ hydrochloric acid ( $\mathrm{HCl}$ or $9.2 \%$ volume concentration versus fluid volume extracted) is best suited to precipitate withdrawal norbixin freedom. After drying at $50{ }^{\circ} \mathrm{C}$ precipitate obtained powder precipitated with $44.25 \%$ norbixin.

\section{References}

[1] Vo Van Chi. 1998. Herbs Commonly Found in Vietnam. Vol. 1. Hanoi: Science Publishing House, 145.

[2] Le Thi Anh Dao and Phan Thi Thuc. 2000. "Extraction of Red Food Dye Annatto (Bixa orellana L.) in Vietnam.” In the Collection of Scientific Works Conference and Organic Chemistry Technologies Nationwide for the Second Time, Quy Nhon, Binh Dinh, 9/2000. Vietnam Chemical Society, 264-8.

[3] Nachtigall, A. M., Silva, P. I., Bertoldi, M. C., and Stringheta, P. C. 2009. "Estudo da saponificação em pigmentos de urucum.” Ciênc. Tecnol. Aliment. Campinas 29 (4): 873-8.

[4] Silva, P. I., Nachtigall, A. M., and Stringheta, P. C. 2009. "Fatores que influenciam a reação de saponificação dos carotenóides presentes no urucum (Bixa orellana L.).” Ciênc. agrotec., Lavras 33 (Edição Especial): 1892-7.

[5] Mantovani, N. C., Grando, M. F., Xavier, A., and Otoni, W. C. 2013. “Avaliação de genótipos de urucum (Bixa orellana L.) por meio dacaracterização morfológica de frutos, produtividade de sementes e teor de bixina.” Ciência Florestal, Santa Maria 23 (2): 355-62. 
[6] Hyman, E. L., Chavezt, R. J., and Skibiak, J. 1990. "Reorienting Export Production to Benefit Rural Producers: Annatto Processing in Peru.” Journal of Rural Studies 6 (1): 85-101.

[7] Haque, M. 2011. "Evaluation of Natural Colour from Annatto Seeds for Pharmaceutical Use.” M.Sc. thesis,
Rajiv Gandhi University of Health Sciences, Karnataka, Bangalore, India.

[8] Dinda, S. C., Mukherjee, B., Damodharan, N., and Barik, B. B. 2008. "Annatto Seed Color as Natural Coloring Agent in Oral Dosage Forms.” Int. J. Pharm. Sci. Tech. 1 (1): 10-4. 